\title{
Effect of Autoclave Pretreatment on Biogas Production through Anaerobic Digestion of Green Algae
}

\author{
RuiZhe Feng ${ }^{1}$, QiaoYan Li², Asad A. Zaidi ${ }^{3}$ Hao Peng ${ }^{4}$, Yue Shi ${ }^{\text {* }}$ \\ ${ }^{1}$ College of Power and Energy Engineering, Harbin Engineering University, 145 Nantong Road, Nangang District, 150001 Harbin, \\ China \\ 2 School of Environment and Planning, Liaocheng University, 1 Hunan Road, 252000 Liaocheng City, Shandong Province, China \\ ${ }^{3}$ Department of Engineering Sciences, PN Engineering College, National University of Sciences and Technology, 74800 Karachi, \\ P. O. B. 75350 , Pakistan \\ ${ }^{4}$ Department of Chemical Engineering, Imperial College London, South Kensington Campus, Exhibition Road, SW7 2AZ London, \\ UK \\ * Corresponding author, e-mail: shiyue@hrbeu.edu.cn
}

Received: 18 February 2021, Accepted: 16 June 2021, Published online: 26 July 2021

\begin{abstract}
Anaerobic Digestion (AD) is one of the most widely used methods in the field of sustainable bioenergy production from various feedstock. One such feedstock is algae waste which has become an increasingly serious environmental problem. AD of algal biomass is hindered by the presence of resistant cell walls; hence a pretreatment step is usually required to decompose the cell wall structure. This study uses green algae (Enteromorpha) and anaerobic sludge as raw materials to explore the impact of autoclave (AC) pretreatment on biogas production. $\mathrm{AC}$ pretreatment was performed at $120^{\circ} \mathrm{C}$ and $80^{\circ} \mathrm{C}$. The cumulative biogas production of the $120{ }^{\circ} \mathrm{C} \mathrm{AC}$ pretreatment, $80^{\circ} \mathrm{C} \mathrm{AC}$ pretreatment and control group were $600 \mathrm{~mL}, 450 \mathrm{~mL}$ and $400 \mathrm{~mL}$, respectively. The results showed that $\mathrm{AC}$ pretreatment improved the biodegradability of biomass as $120^{\circ} \mathrm{C} \mathrm{AC}$ pretreatment group achieved higher degradation rate of cells (95.99 \%). The energy evaluation showed that the net energy ratio of the $120^{\circ} \mathrm{C}$ AC pretreatment group was 1.07 , indicating high overall energy gain via AD process. The experimental data is further modeled by using Modified Gompertz Model (MGM) and Logistic Function Model (LFM). To check the applicability of better model for this AD process, an Akaike Information Criteria (AIC) test was performed. AIC showed that the MGM is basically consistent with the experimental data and more reliable for prediction modeling of Enteromorpha AD.
\end{abstract}

Keywords

Anaerobic Digestion (AD), biogas, green algae, kinetic models, autoclave pretreatment

\section{Introduction}

The world is facing a significant energy crisis due to increased energy demand $[1,2]$. The conventional sources alone cannot fulfill this ever-increasing demand for energy because conventional energy sources are mostly nonrenewable energy sources that tend to deplete with time [3]. Therefore, it is a fact that there is a great need for energy sources that do not deplete and damage the environment $[4,5]$. Renewable energy sources are on the other hand ecofriendly. One such source for energy harvesting is biomass [6].

Biofuels can be produced by utilizing locally available organic feedstock [7]. Various methods are available for organic matter to energy conversion, however Anaerobic Digestion (AD) is among the most preferable specifically for biogas production [8]. AD is a common and useful solution to handle organic waste, and ferment waste to methane and hydrogen [9]. Biohydrogen has been regarded as a clean and renewable form of energy with high calorific value [10]. At present, the method with mild reaction conditions and good environmental benefits that has been widely studied is biological hydrogen production. Among them, the dark fermentation does not rely on light, the reactor structure is simple, and it is widely welcomed [11]. The process of anaerobic fermentation production capacity is a complex biochemical process. In the process, a variety of anaerobic microorganisms work together to degrade and transform organic waste into hydrogen, methane, carbon dioxide. The nutrients are required for its own growth and 
reproduction. This complex process can be divided into the following four stages. The hydrolysis stage is the process of decomposing very complex insoluble macromolecular organic aggregates into simple soluble monomers or dimers. The fermentation stage is a process in which microorganisms use the small molecule products of the hydrolysis process to convert into nutrients and volatile fatty acids. The hydrogen production and acetic acid production stage is a complex process in which different types of microorganisms use the final products of the fermentation stage such as volatile fatty acids, alcohol, lactic acid, etc., are converted into acetic acid, hydrogen. In the methanogenesis stage, there are two different ways to produce methane due to the action of different microbial groups [12].

Hydrogen has become the focus of attention due to its high combustion efficiency, pollution-free combustion products and convenient transportation. The marine algae have high polysaccharide content, up to $50 \%$, the monosaccharide in kelp polysaccharide, which are good substrates for microbial fermentation. The related literature shows that many microorganisms can ferment hydrogen by using a variety of pure monosaccharides, but they all take pure monosaccharide as the substrate, which leads to high economic cost. Therefore, anaerobic fermentation of the hydrolysate of algae rich in monosaccharides which are available by many microorganisms will greatly reduce the cost of biological hydrogen production, Therefore, the study of anaerobic fermentation of algae as raw material has a broad application prospect.

In order to deal with the refractory nature of algae and the complexity of its structure, the pretreatment process can convert macromolecular substances into small molecular substances. Its cellulose content ratio is large, and the biodegradability depends on the degree to which cellulose and hemicellulose are encapsulated by lignin [13]. Cellulose and hemicellulose can be biological degradable, but lignin is difficult to degrade, when lignin is wrapped on the surface of cellulose and hemicellulose. Enzymes cannot contact the cellulose and hemicellulose phase leading to slow degradation. Whether extracellular enzymes can effectively contact the substrate becomes the key to affect the hydrolysis rate [14]. For that reason, there are number of pretreatment methods used to improve hydrolysis stage in AD process [15-17]. These methods include mechanical, physical, thermal and chemical treatments. Mechanical techniques utilize bead milling and high-pressure homogenizer for algae cell disruption and pretreating Laminaria spp. Physical techniques apply physical forces to reduce crystallinity of cellulose by breaking down its structure. Chemical techniques utilize different chemicals such as different strengths enzymes and catalyst to enhance biogas yield. Thermal pretreatment involve heat supply to break the chemical bonds in cell wall and also to increase the soluble rate of cell components $[18,19]$. One of the most useful pretreatment methods for $\mathrm{AD}$ of algal biomass is thermal pretreatment. Lower energy requirements and high energy production with higher biogas yield is an advantage compare with physical pretreatment methods [15]. Autoclaving is one of physical pretreatment methods which operate at a temperature of $121{ }^{\circ} \mathrm{C}$ and pressure of $103.421 \mathrm{kPa}$ [20]. Deepanraj et al. [21] have studied the effect of autoclaving pretreatment on the $\mathrm{AD}$ of chicken manure and kitchen waste. The results showed that by using an autoclave to pretreat the substrate, the cumulative biogas production was increased by about $4.67 \%$ as compared to untreated one. Another study conducted by Liu et al. [22] significantly increased the biomethane gas potential and kinetics of forest samples of hazelnuts by using autoclaving pretreatment to digest two forest residues (hazelnuts and acacia) and two agricultural lignocellulose residues (Barley straw and bagasse), the conditions were set to autoclave at $121{ }^{\circ} \mathrm{C}$ for 30 minutes.

Enteromorpha is fresh water algae. It contains a lot of carbohydrates, cellulose and protein [23]. Enteromorpha is a very important economic seaweed. It grows and reproduces rapidly. With the aggravation of seawater eutrophication in recent years, combined with the comprehensive influence of climate warming and other favorable factors, Enteromorpha shows a rapid growth, which once became a "green tide" that shocked the world. Since 2007, green tide natural disasters have broken out in China for nine consecutive years. In 2008, only 1.2 million tons of green tide algae (Enteromorpha) were fished in Qingdao sea area. The annual amount of green tide in Fujian coastal areas is more than 100000 tons. The outbreak of green tide not only caused the death of fish and shrimp, the deterioration of water quality, but also caused more serious environmental problems because of its huge biomass difficult to deal with. There exist no place to landfill, and the retrieved Enteromorpha will rot and stink in a short time [24]. It has become an irresistible trend to use marine algae to study fermentative hydrogen production. However, at the current technical level, there are still many problems in the efficient mass production of algae biofuels. Therefore, exploring more reasonable utilization of algae resources, studying efficient treatment 
methods of algae, and improving the efficiency of algae fermentation for hydrogen production are the critical bottleneck technologies to solve the current utilization of Enteromorpha. This study is closely following the current situation of energy shortage, to explore the experimental method of efficient pretreatment of green tide algae Enteromorpha, which laid the foundation for large-scale use of algae to prepare bioenergy.

In our previous study [12], effect of microwave pretreatment on Enteromorpha AD was conducted, the response surface method was used to optimize it to further increase the hydrogen production. In present study, autoclave pretreatment is applied for Enteromorpha AD. Energy analysis is carried out to find out feasibility of autoclave pretreatment to obtain positive energy balance. Moreover, kinetic parameters of AD are determined by established prediction models.

\section{Materials and methods}

\subsection{Raw materials}

The anaerobic sludge used in the experiments was taken from Wenchang Sewage Treatment Plant in Harbin, China. Because the sludge from sewage treatment plant is aerobic sludge, it is necessary to cultivate anaerobic sludge. The sludge was aerated and cultivated for 1 to 2 weeks. During the culture, nutrients were added at the ratio of 300:5:1 with glucose, $\mathrm{NH}_{4} \mathrm{Cl}$, and $\mathrm{KH}_{2} \mathrm{PO}_{4}$. The sludge was brown, with well settlement $[25,26]$. Enteromorpha used in the experiment was obtained from the Institute of Hydrobiology, Chinese Academy of Sciences, and dried in a dry box. The morphology of dried Enteromorpha is shown in Fig. 1. In Enteromorpha it contains $13.20 \%$ protein, $1.06 \%$ fat and $21.77 \%$ ash [10].

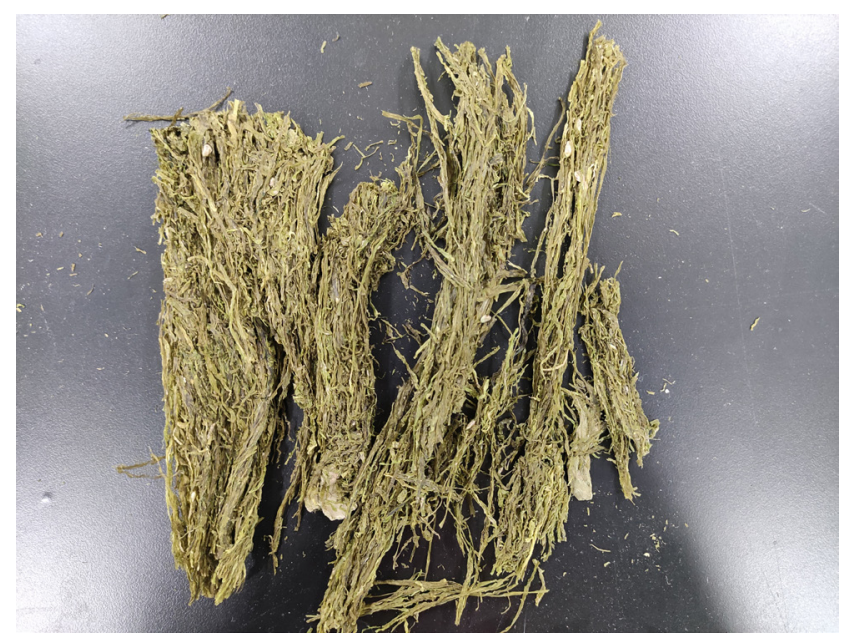

Fig. 1 Macromorphology of Enteromorpha

\subsection{Experimental setup}

Before $\mathrm{AD}$, autoclave pretreatment was performed by autoclave (MJ-78A, STIK GROUP LLC, USA). The set high temperature and high pressure pretreatment conditions are: solid-liquid ratio and pretreatment time are 20:1 and 30 minutes, respectively, and the temperature is $120^{\circ} \mathrm{C}$ [27]. The laboratory glass bottle (working volume $=500 \mathrm{~mL}$ ) was used as a biological digester, and then a batch AD experiment was performed through an anaerobic batch system. The solid-liquid ratio determined by previous experiments is $1: 20$, and $\mathrm{pH}$ was adjusted to 7 . Rubber plugs were used to seal the biodigester. Before the experiment, nitrogen was used to purge for 5 minutes to form an anaerobic environment inside digesters. The environment in the digester is maintained at $37{ }^{\circ} \mathrm{C}$ and a mixing speed of $150 \mathrm{rpm}$.

\subsection{Analytical methods}

The main quantities that need to be measured in the experiment are Total Chemical Oxygen Demand (TCOD), Soluble Chemical Oxygen Demand (SCOD) and reducing sugars [28]. After pretreatment, cell lysis rate is calculated to analyze the effect of high temperature and high pressure pretreatment by following formula [29]:

Cell Lysis Rate $(\%)=\frac{\operatorname{SCOD}_{T}-\mathrm{SCOD}_{O}}{\mathrm{TCOD}_{O}-\mathrm{SCOD}_{O}} \times 100$.

Among them, $\mathrm{SCOD}_{T}$ represents the release of SCOD during $\mathrm{AD}$, and $\mathrm{SCOD}_{O}$ and $\mathrm{TCOD}_{O}$ represent the SCOD and TCOD values of Enteromorpha mass. A spectrophotometer (dr3900, HACH, USA) with a maximum wavelength $\left(\lambda_{\max }\right)$ of $550 \mathrm{~nm}$ was used to determine the glucose concentration. A $50 \mathrm{~mL}$ syringe was used to extract a biogas sample to measure hydrogen, and use 176 thermal conductivity detector-flame ionization detector (TCD-FID) to inject $1750.5 \mathrm{~mL}$ biogas into a gas chromatograph (SP-2100A, BFRL, USA), determine $177 \%$ of the biogas Hydrogen content ( $/ \mathrm{v})$. The production of biogas is measured twice a day, and the composition of the biogas is observed once. In order to reduce possible errors, each experiment was carried out three times and the average value was presented. Scanning electron microscopy (SEM, JCM5000 Hitachi Japan) was performed on the pretreated samples, TG-DTG was carried out by using Thermogravimetric analyzer (TGA Q50 TA INSTRUMENTS USA), and the results were analyzed by one-way analysis of variance with origin 8.0 software. $P<0.05$ was considered statistically significant. 


\subsection{Energy analysis}

Energy evaluation is an important indicator that can calculate output and input energy. Input energy and output energy are calculated using Eqs. (2), (3) [30]. The ratio of energy output to energy input is the energy ratio calculated by Eq. (4).

$E_{\text {in }}=3600 P \times t$,

where:

- $E_{\text {in }}=$ Energy input $(\mathrm{kJ})$

- $P=$ Power required for Autoclave pretreatment $(\mathrm{kW})$

- $t=$ running time $(\mathrm{h})$.

$E_{\text {out }}=\frac{\Delta Q \times V \times \varepsilon}{10^{3}}$,

where:

- $E_{\text {out }}=$ Energy output $(\mathrm{kJ})$

- $\Delta Q=$ Hydrogen yield $\left(\mathrm{L} \mathrm{H}_{2} / \mathrm{L} / \mathrm{d}\right)$

- $V=$ Effective volume (L)

- $\varepsilon=$ Calorific value of hydrogen $\left(120,000 \mathrm{~kJ} / \mathrm{m}^{3}\right)$.

$\Delta E=\frac{E_{\text {out }}}{E_{\text {in }}}$

\subsection{Mathematical kinetic models}

Modified Gompertz model and Logistic function model as indicated by Eqs. (5), (6) are used to analyze the autoclave pretreatment. Both models are used to determine kinetic parameters via origin 8.0 software. The iterative method is mainly used in the calculation process, and the Levenberg-Marquardt (L-M) algorithm is used to evaluate the reaction kinetics [31].

$$
\begin{aligned}
& B=B_{P} \times \exp \left(-\exp \left(\operatorname{MBPR} \frac{2.7183}{B_{P}}(\mathrm{BPDT}-t)+1\right)\right), \\
& B=\frac{B_{P}}{1+\exp \left(4 \mathrm{MBPR} \frac{\mathrm{BPDT}-t}{B_{P}}+2\right)},
\end{aligned}
$$

where:

- $B=$ Cumulative biogas volume at digestion time $t(\mathrm{~mL})$

- $B_{P}=$ Biogas production potential $(\mathrm{mL})$

- $\mathrm{MBPR}=$ Maximum Biogas Production Rate $(\mathrm{mL} / \mathrm{h})$

- $\mathrm{BPDT}=$ Biogas Production Delay Time (h)

- $t=$ Total digestion time (h).

The Akaike Information Criteria (AIC) is used to evaluate the fitting effects of two different models. For each model, the AIC value and the Akaike weight value are calculated by Eqs. (7), (8):
$\mathrm{AIC}=\left\{\begin{array}{ll}N \ln \frac{\mathrm{RSS}+2 K}{N}, & \text { when } \frac{N}{K} \geq 40 \\ N \ln \frac{\mathrm{RSS}}{N}+2 K+\frac{2 K(K+1)}{N-K-1}, & \text { when } \frac{N}{K}<40\end{array}\right.$,

Akaike weight $=e^{\wedge}(-0.5 \Delta \mathrm{AIC}) /\left(1+e^{\wedge}(-0.5 \Delta \mathrm{AIC})\right)$,

where:

- $N=$ Number of points

- $\mathrm{RSS}=$ Residual Sum of Square

- $K=$ Number of model parameters

- $\triangle \mathrm{AIC}=$ The relative difference between the two AIC values

\section{Results and discussion}

\subsection{Pretreatment effect on Enteromorpha}

The main purpose of pretreatment was to increase the amount of simple forms, which required the decomposition of complex structures, shorten the hydrolysis time, and increased the reaction rate. Scanning Electron Microscope (SEM) was used to observe the physical structure changes of algae. Fig. 2 shown the morphology of the substrate pretreated by the autoclave. For the original substrate, it had a compact structure with small holes on the surface, as shown in Fig. 2 (a). The autoclave pretreatment shown in Fig. 2 (b) resulted in slight crushing and decomposition, which also showed that a large number of physical effects affected the physical wood fiber structure of the solid digestion, and the substrate surface was substantially damaged.

It can be noticed from the TG-DTG curves in Fig. 3 of autoclave pretreatment with the temperature increases; there are four stages in the pyrolysis of biomass. The first area is the water analysis process, and the temperature range is: $50-168{ }^{\circ} \mathrm{C}$. As the temperature increases, the moisture in the biomass begins to precipitate, and the derivative curve fluctuates. The second area is a slow decomposition process with a temperature range of 168 $245^{\circ} \mathrm{C}$. A small amount of weight loss occurs in this area, which may be the occurrence of understanding and "glass condition transition", preparing for rapid pyrolysis, at which time small molecule compounds such as $\mathrm{CO}, \mathrm{CO}_{2}$ and $\mathrm{H}_{2}$ are released. The second region is the rapid pyrolysis process, which is the main stage of pyrolysis. Most of the weight loss of the sample occurs in this region, and the weight loss rate accounts for more than $80 \%$ of the total weight loss. The DTG curve also has a distinct peak in this region. The temperature range 


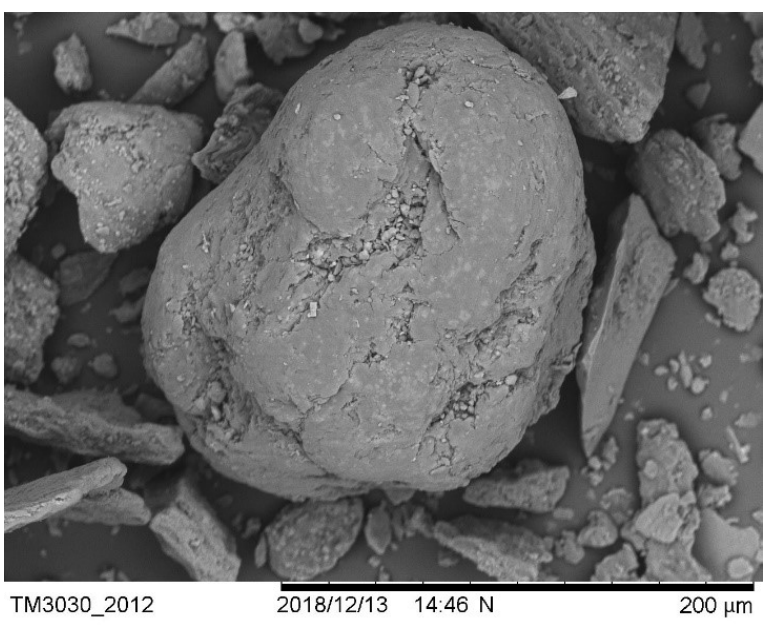

(a)

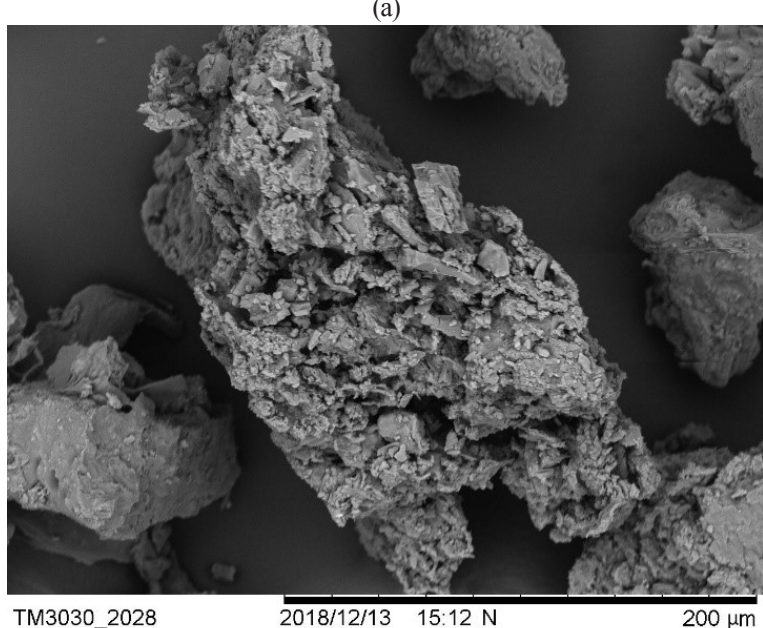

(b)

Fig. 2 Microstructure change of autoclave pretreatment (a) unpreatreated substrate (b) autoclave pretreated substrate

for this area is Brassica $245-560{ }^{\circ} \mathrm{C}$. The fourth stage is the slow decomposition and volatilization process of the residue and inorganic ash.

\subsection{AC effect on biogas and hydrogen production}

It can be seen that compared with the control group, the biogas production has been improved, indicating that the autoclave pretreatment has a positive effect on the AD of Enteromorpha. The results are shown in Fig. 4. As shown, the gas production at the initial stage $(0-36 \mathrm{~h})$ was in low level, the slope of the curve was small, and the gas production increased slowly. When AD continued in the middle stage ( $36 \mathrm{~h}-84 \mathrm{~h}$ ), the gas production of the three groups increased significantly especially the $120{ }^{\circ} \mathrm{C}$ group, and the slope of the curve also began to increase. At $84 \mathrm{~h}$, the cumulative gas production of the three groups exceeded $200 \mathrm{~mL}$, but there was no significant difference between them. When AD continued until

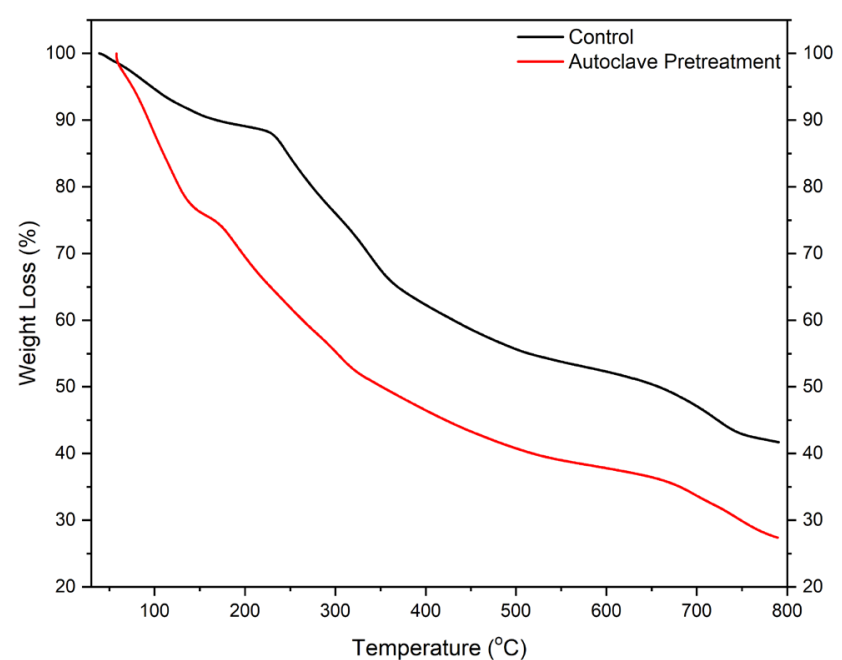

(a)

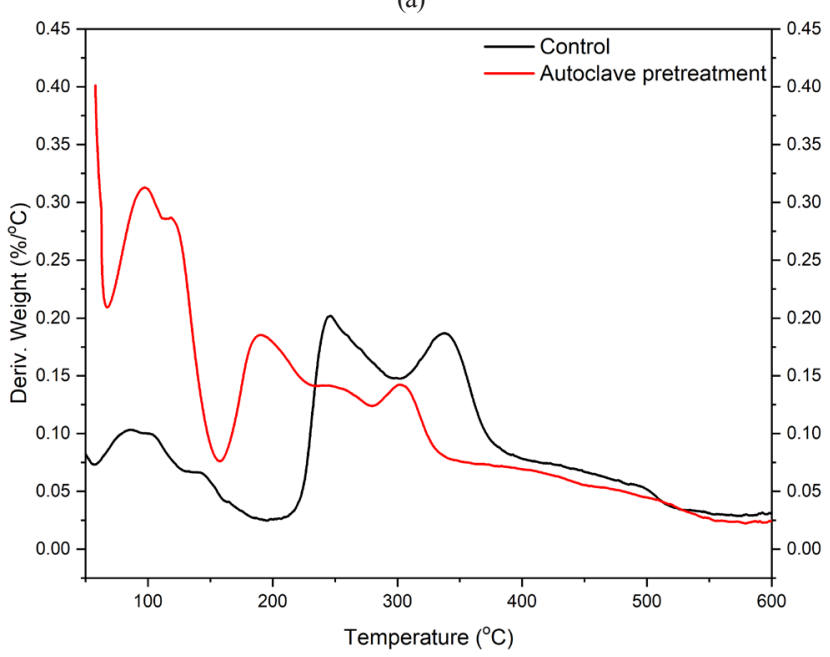

(b)

Fig. 3 Thermal Gravity Analysis for substrate (a) TG (b) DTG

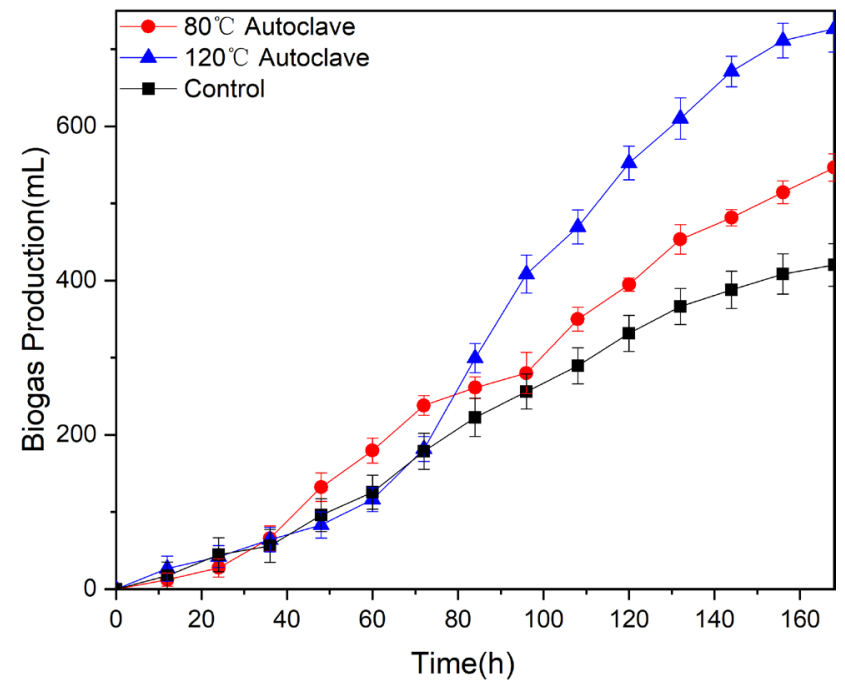

Fig. 4 Biogas production influenced by different autoclave temperature

$84 \mathrm{~h}$, it was found that the gas production of autoclave pretreatment group at $120{ }^{\circ} \mathrm{C}$ began to increase significantly, and the growth rate exceeded the control group 
and $80{ }^{\circ} \mathrm{C}$ pretreatment group. $120{ }^{\circ} \mathrm{C}$ group only used $96 \mathrm{~h}$ to exceed control group $168 \mathrm{~h}$ gas production amount. As AD continues, there was a big difference between 3 groups. In the later stage of AD ( $84 \mathrm{~h}-168 \mathrm{~h})$, the gas production growth rate of $80{ }^{\circ} \mathrm{C}$ group also exceeded the control group, but the increase was not obvious. At the end stage of the AD (168 h), the cumulative gas production of $120{ }^{\circ} \mathrm{C}$ autoclave pretreatment group was as high as $600 \mathrm{~mL}$, which was the most significant increase compared with the $80{ }^{\circ} \mathrm{C}$ autoclave pretreatment group $(450 \mathrm{~mL})$ and the control group $(400 \mathrm{~mL})$.

Table 1 showed the proportion of hydrogen in the biogas fermentation production process of the control group and the other two groups at $128 \mathrm{~h}$. It can be seen that the hydrogen content of the control group was at a low level of only $16.48 \%(\mathrm{v} / \mathrm{v})$. The hydrogen content of $80^{\circ} \mathrm{C}$ autoclave pretreatment group increased to $19.4 \%(\mathrm{v} / \mathrm{v})$, and the hydrogen content of $120{ }^{\circ} \mathrm{C}$ autoclave pretreatment group increased significantly, which up to $32.93 \%(\mathrm{v} / \mathrm{v})$. Therefore, it was known that high temperature and high pressure pretreatment had a good effect on the hydrogen production process.

The low gas production in the early stage of the experiment can be explained as: in the initial stage of $\mathrm{AD}$, the main digestion process in the mixed culture solution is the hydrolysis process, and the macromolecular organic matter such as cellulose and protein in green algae (Enteromorpha) was decomposed into small molecular organic compounds. The dominant strains are bacteria that promote hydrolysis, such as cellulolytic bacteria, carbohydrate decomposition bacteria, lipolytic bacteria, and cellulolytic bacteria. The hydrogen production of hydrogen producing bacteria is not obvious, so the yield is small. As the fermentation progresses, small molecules of organic matter in the fermentation bottle begin to accumulate, which provides sufficient fermentation substrate for the hydrogen-producing acetogens and homoacetogenic bacteria to accelerate the hydrogen production rate. This phenomenon occurred in the middle stage. In addition, the biogas amount showed the catalytic effect of high temperature autoclaving pretreatment on hydrogen production $[25,26]$.

Table 1 Hydrogen content by different autoclave temperature

\begin{tabular}{lccc}
\hline & Control & $80{ }^{\circ} \mathrm{C}$ & $120^{\circ} \mathrm{C}$ \\
\hline Biogas amount $(\mathrm{mL})$ & 405 & 455 & 598 \\
Hydrogen ratio $\%(\mathrm{v} / \mathrm{v})$ & 16.48 & 19.4 & 32.93 \\
\hline
\end{tabular}

\subsection{Energy analysis}

The energy evaluation of the whole fermentation process is shown in Fig. 5. It evaluated the feasibility of the pretreatment effect of the autoclave. As shown, for each case, the energy output which mainly includes the heat value generated by hydrogen combustion (ie. output energy, $\left.E_{\text {out }}\right)$ is divided by the energy required for autoclave pretreatment such as the electric power used by autoclave (ie energy input, $E_{i n}$ ). The results showed that the $120^{\circ} \mathrm{C}$ group has an energy ratio greater than 1 . This indicates that the increase in hydrogen production obtained is sufficient to cover the input energy of the system. The $80^{\circ} \mathrm{C}$ group cannot reach 1 because the hydrogen content is less. Compared with the $120{ }^{\circ} \mathrm{C}$ group, the net energy gain is the largest when the energy ratio reaches 1.07 .

\subsection{Cell lysis and total carbohydrate concentration}

Fig. 6 showed the effect of autoclave pretreatment on biodegradability of microalgal biomass which called the degree of cell lysis rate (\%). It can be found that the $80{ }^{\circ} \mathrm{C}$ pretreated group and control group had the same degree of cell lysis for the first 70 hours of $\mathrm{AD}$, which indicate that low temperature cannot able to break down the cell wall. This result is in agreement with biogas production data. In contrast, $120{ }^{\circ} \mathrm{C}$ pretreated group showed a better cell lysis rate, and in soluble phase it had more organic matter. $120{ }^{\circ} \mathrm{C}$ pretreated groups obtained the highest cell lysis of $95.99 \%$.

Fig. 7 showed the COD content of $80^{\circ} \mathrm{C}, 120^{\circ} \mathrm{C}$ group and control group for every 24 hours during the fermentation process. It can be seen that, the $80{ }^{\circ} \mathrm{C}, 120^{\circ} \mathrm{C}$ group and control group both increased significantly in the early stage of fermentation (within 48 hours). After 48 hours,

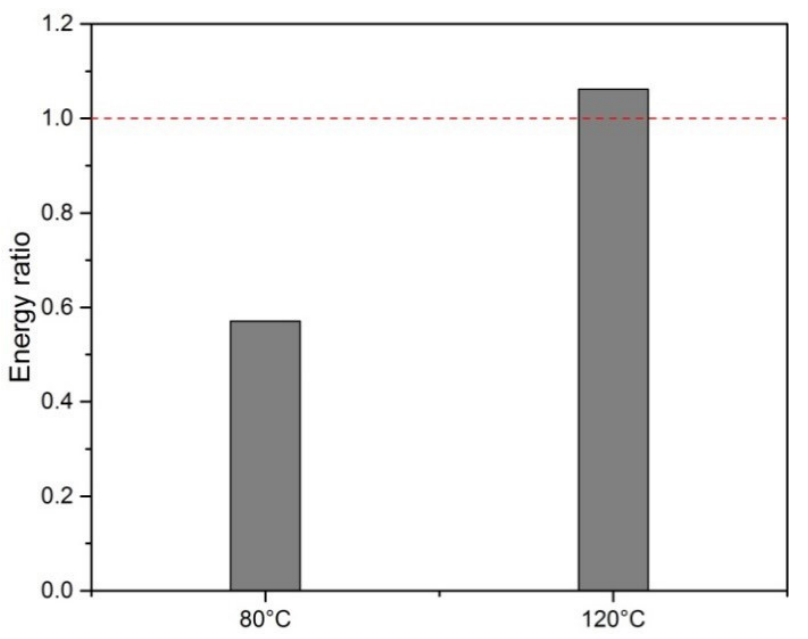

Fig. 5 Energy analysis for different autoclave temperature 


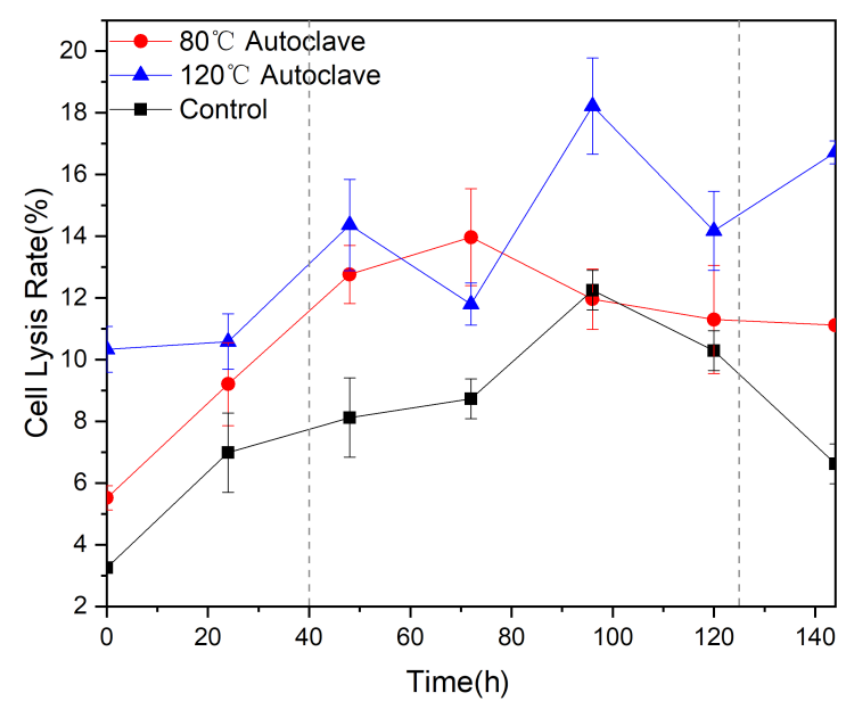

Fig. 6 Microalgal biomass cell lysis rate

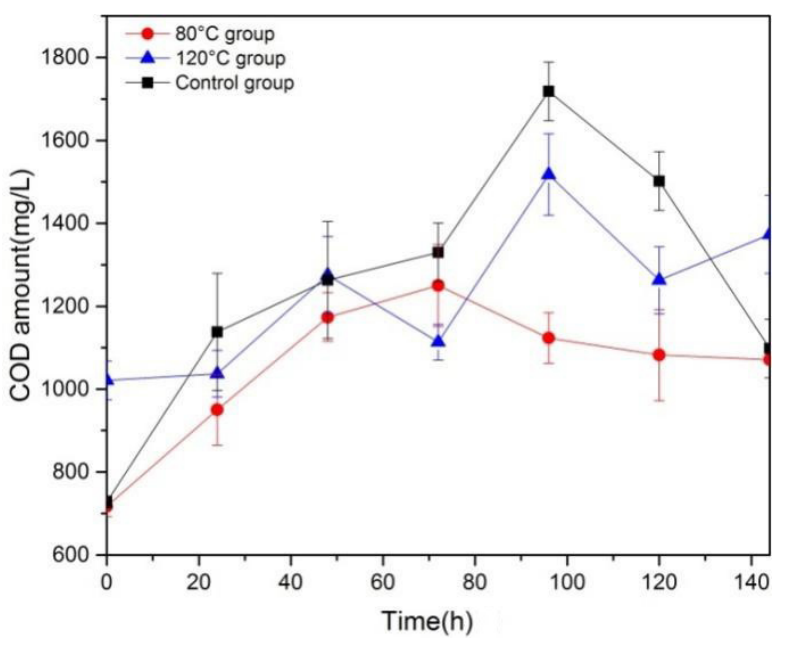

Fig. 7 Changes in COD concentration during the AD

the rate of increase for control group COD content tend to be stable. It can be found that the $80{ }^{\circ} \mathrm{C}$ and $120{ }^{\circ} \mathrm{C}$ group reached a high peak also had a high growth rate. When the reaction proceeded to the end stage of the fermentation period (especially after $120 \mathrm{~h}$ ), the COD content decreased in each group. This trend is maintained until the reaction stops.

This trend is also in line with expectations. In the initial stage of fermentation, the biogas production is not much. The reaction of this process is mainly the hydrolysis process of microorganisms. The organic matter of large parts is decomposed into small molecular organic substances, which leads to dissolution. The amount of organic solutes in the solution is greatly increased. When the gas production rate is greatly accelerated, the rate of increase of COD content begins to decrease. This fact showed that small molecular organic solutes dissolved in the solution enter the cells through the cell membrane of the microorganisms for anaerobic fermentation to produce biogas, resulting in dissolution of the fermentation [32].

The total carbohydrate (polysaccharide) in the fermentation substrate provided the main raw material for $\mathrm{AD}$, and is also the initial resource for fermentation. The total carbohydrate is fermented by hydrolysis into monosaccharide for direct using by bacteria. Its content reflected the amount of total sugar dissolved in the extract and affects the fermentation process. During the fermentation process, the total sugar content will change with the digestion and degradation of the relevant bacteria.

As shown in Fig. 8, the total carbohydrate content generally decreased. In the initial stage of fermentation, the average carbohydrate content in the three treatments was decreased slowly. Between the middle stage, the total carbohydrate content began to decrease dramatically. The total carbohydrate content in the bottle began to stabilize during the end stage, and this trend continued until the end of the reaction [31].

\subsection{Kinetic models}

Tables 2 and 3 show the Gompertz and logistic model data respectively. Figs. 9 and 10 show the difference between predicted and actual gas production. The improved Gompertz model showed that the maximum gas production (MBPR) of the control group was $3.56 \mathrm{~mL} / \mathrm{h}$, the pretreatment group was $4.13 \mathrm{~mL} / \mathrm{h}$ at $80{ }^{\circ} \mathrm{C}$, and $7.74 \mathrm{~mL} / \mathrm{h}$ at $120^{\circ} \mathrm{C}$. On the other hand, in the logistic model, the maximum gas production (MBPR) of the control group, $80{ }^{\circ} \mathrm{C}$ and $120^{\circ} \mathrm{C}$ groups were $3.89,4.44$, and $8.39 \mathrm{~mL} / \mathrm{h}$,

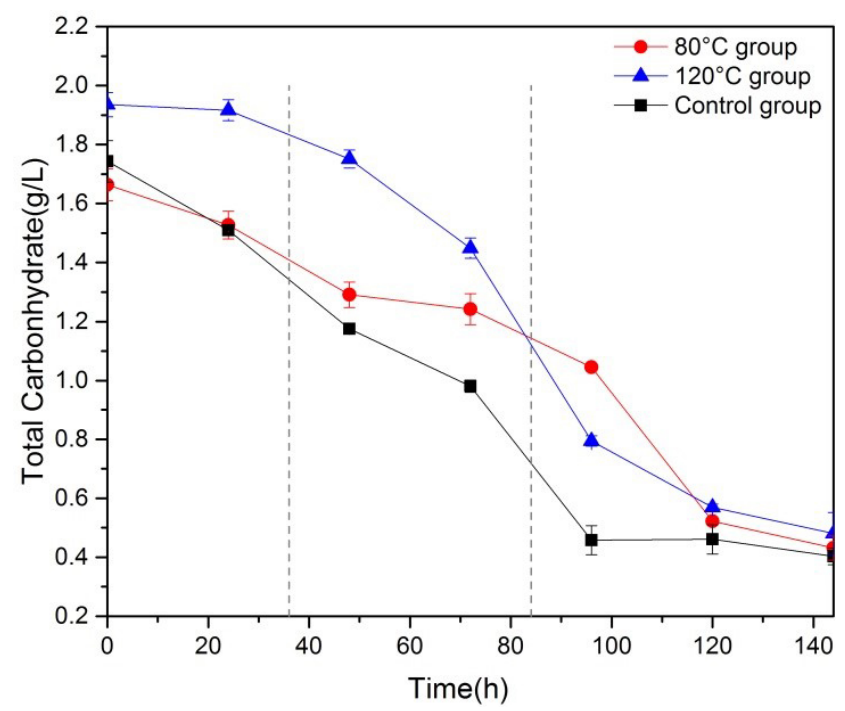

Fig. 8 Changes in total carbohydrate concentration during the AD 
Table 2 Parameters of modified Gompertz model

\begin{tabular}{lccc}
\hline Parameter & \multicolumn{3}{c}{ Treatments } \\
& Control & 80 & 120 \\
\hline$B_{P}(\mathrm{~mL})$ & 501.39 & 640.75 & 809.75 \\
MBPR $(\mathrm{mL} / \mathrm{h})$ & 3.56 & 4.13 & 7.74 \\
BPDT $(\mathrm{h})$ & 0.905 & 0.791 & 1.89 \\
$R^{2}$ & 0.99867 & 0.99244 & 0.99647 \\
Predicted Biogas Yield (mL) & 426.982 & 525.019 & 723.661 \\
Measured Biogas Yield (mL) & 427 & 534 & 715 \\
$\begin{array}{l}\text { Difference between } \\
\text { measured and predicted }\end{array}$ & $4.68 \mathrm{E}-3$ & 1.71 & 1.21 \\
biogas yield $(\%)$ & & & \\
\hline
\end{tabular}

Remarks: $B_{P}$, Biogas production potential; MBPR, Maximum Biogas Production Rate; BPDT, Biogas Production Delay Time; $R^{2}$, Correlation Coefficient

Table 3 Parameters of Logistic Function model

\begin{tabular}{lccc}
\hline Parameter & \multicolumn{3}{c}{ Treatments } \\
& Control & 80 & 120 \\
\hline$B_{P}(\mathrm{~mL})$ & 439.21 & 557.23 & 729.08 \\
MBPR (mL/h) & 3.89 & 4.44 & 8.39 \\
BPDT (h) & 1.18 & 1.05 & 2.10 \\
$R^{2}$ & 0.99453 & 0.98324 & 0.99784 \\
Predicted Biogas Yield (mL) & 417.387 & 516.893 & 705.94056 \\
Measured Biogas Yield (mL) & 427 & 534 & 715 \\
$\begin{array}{l}\text { Difference between } \\
\text { measured and predicted }\end{array}$ & 2.30 & & \\
biogas yield (\%) & & & 1.27 \\
\hline
\end{tabular}

Remarks: $B_{P}$, Biogas production potential; MBPR, Maximum Biogas Production Rate; BPDT, Biogas Production Delay Time; $R^{2}$, Correlation Coefficient

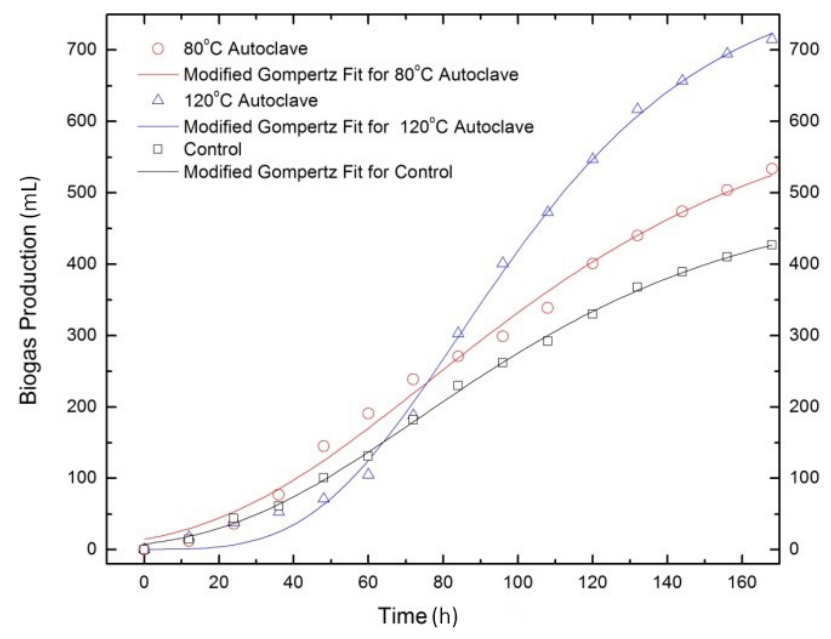

Fig. 9 Modified Gompertz Fit for experimental data

respectively. The calculation results show that autoclave pretreatment can increase biogas production and reduce lag time. The reason is that the autoclave pretreatment increases the hydrolysis rate of the cell wall and reduces

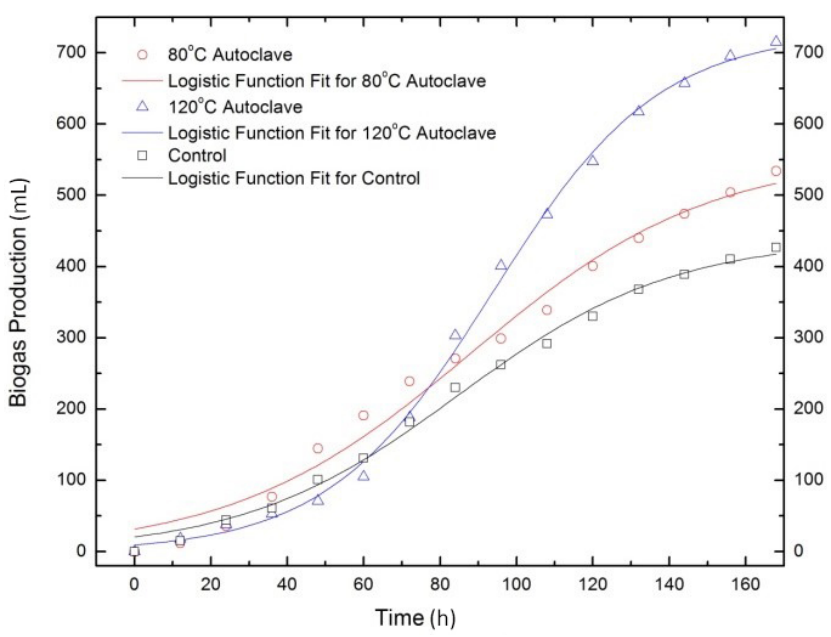

Fig. 10 Logistic Function Fit for experimental data

the lag phase. From the correlation coefficient, the two coefficients are $99.87 \%$ and $98.32 \%$ respectively, which shows that the fitting conditions are better.

Table 4 showed Akaike Information Criterion (AIC) test for the fitting results. AIC suggests that modified Gompertz model has a lower AIC value and hence proved to be a better model to use in this case.

\section{Conclusions}

This experiment verified that autoclave pretreatment can improve the biodegradability of green algae and enhance the anaerobic fermentation process. In the batch fermentation experiment, the cumulative gas production of the $120^{\circ} \mathrm{C}$ autoclave pretreatment group was as high as $600 \mathrm{~mL}$, which was the largest increase compared with the $80{ }^{\circ} \mathrm{C}$ autoclave pretreatment group $(450 \mathrm{~mL})$ and the control group $(400 \mathrm{~mL})$. The energy calculation results show that the output to input energy ratio of the $120^{\circ} \mathrm{C}$ group is 1.07 , and the fermentation system can generate net energy output. The cell lysis rate in the $120{ }^{\circ} \mathrm{C}$ group was the highest, which was $95.99 \%$. The experimental data is modeled by the improved Gompertz and Logistic function model. The Akaike Information Criteria (AIC) test shows that the experimental data of the Gompertz model is more fitting than the Logistic function model.

Table 4 Results for Akaike's Information Criterion (AIC) Test

\begin{tabular}{lcccc}
\hline Model & RSS & $N$ & AIC & $\begin{array}{l}\text { Akaike } \\
\text { Weight }\end{array}$ \\
\hline Modified Gompertz Model & 3054.101 & 15 & 91.742 & 0.99746 \\
Logistic Function Model & 6772.091 & 15 & 103.687 & 0.00254 \\
\hline
\end{tabular}

Remarks: RSS, the Residual sum of the square; $N$, Number of Points; AIC, Akaike's Information Criterion 
This study shows that when the microalgae biomass is pretreated in an autoclave at $120{ }^{\circ} \mathrm{C}$, a better anaerobic fermentation effect can be obtained and a positive energy balance can be achieved. In summary, the autoclave pretreatment can provide an effective pretreatment option for the anaerobic fermentation of algae.

\section{References}

[1] Malik, A., Qureshi, S. R., Abbas, N., Zaidi, A. A. "Energy and exergy analyses of a solar desalination plant for Karachi Pakistan", Sustainable Energy Technologies and Assessments, 37, Article number: 100596, 2020.

https://doi.org/10.1016/j.seta.2019.100596

[2] Mehdi, G., Ali, N., Hussain, S., Zaidi, A. A., Shah, A. H., Azeem, M. M. "Design and Fabrication of Automatic Single Axis Solar Tracker for Solar Panel", In: $20192^{\text {nd }}$ International Conference on Computing, Mathematics and Engineering Technologies (iCoMET), Sukkur, Pakistan, 2019, pp. 1-4. https://doi.org/10.1109/ICOMET.2019.8673496

[3] Mushtaq, K., Zaidi, A. A., Askari, S. J. "Design and performance analysis of floating dome type portable biogas plant for domestic use in Pakistan", Sustainable Energy Technologies and Assessments, 14, pp. 21-25, 2016. https://doi.org/10.1016/j.seta.2016.01.001

[4] Faiz Ahmed, S., Mushtaq, K., Ali, A. "Design and Performance Analysis of Ffloating Dome Type Portable Biogas Plant for Domestic Use in Pakistan-manufacturing Cost Optimization", Biotechnology, 15(5), pp. 112-118, 2016.

https://doi.org/10.3923/biotech.2016.112.118

[5] Mondial, C., Gie, D. E. L. É., Gadonneix, P., Kim, Y. D., Meyers, K., Ward, G., Frei, C. "World Energy Resources", World Energy Council, London, UK, 2013.

[6] Cai, Y., Li, X., Zaidi, A. A., Shi, Y., Zhang, K., Feng, R., Lin, A., Liu, C. "Effect of hydraulic retention time on pollutants removal from real ship sewage treatment via a pilot-scale air-lift multilevel circulation membrane bioreactor", Chemosphere, 236, Article number: 124338, 2019.

https://doi.org/10.1016/j.chemosphere.2019.07.069

[7] Vasco-Correa, J., Khanal, S., Manandhar, A., Shah, A. "Anaerobic digestion for bioenergy production: Global status, environmental and techno-economic implications, and government policies", Bioresource Technology, 247, pp. 1015-1026, 2018. https://doi.org/10.1016/j.biortech.2017.09.004

[8] Ma, H., Guo, Y., Qin, Y., Li, Y.-Y. "Nutrient recovery technologies integrated with energy recovery by waste biomass anaerobic digestion", Bioresource Technology, 269, pp. 520-531, 2018. https://doi.org/10.1016/j.biortech.2018.08.114

[9] Shi, Y., Huang, K., Feng, R., Wang, R., Liu, G., Zaidi, A. A., Zhang, K. "Combined MgO nanoparticle and microwave pre-treatment on biogas increase from Enteromorpha during anaerobic digestion", IOP Conference Series: Earth and Environmental Science, 450, Article number: 012025, 2020. https://doi.org/10.1088/1755-1315/450/1/012025

\section{Acknowledgement}

This research was financially supported by the National Key R\&D Plan of China (2017YFC1404605), the Natural Science Foundation of China (Grant No. 51579049 and 51509044), the Fundamental Research Funds for the Central Universities (HEUCFG201820), the High Tech Ship Program (17KJ-003) and the Research on 130,000 GT cruise ship development.

[10] Zaidi, A. A., RuiZhe, F., Malik, A., Khan, S. Z., Bhutta, A. J., Shi, Y., Mushtaq, K. "Conjoint effect of microwave irradiation and metal nanoparticles on biogas augmentation from anaerobic digestion of green algae", International Journal of Hydrogen Energy, 44(29), pp. 14661-14670, 2019.

https://doi.org/10.1016/j.ijhydene.2019.02.245

[11] Wang, J., Yin, Y. "Fermentative hydrogen production using pretreated microalgal biomass as feedstock", Microbial Cell Factories, 17(1), Article number: 22, 2018. https://doi.org/10.1186/s12934-018-0871-5

[12] Feng, R., Zaidi, A. A., Zhang, K., Shi, Y. "Optimisation of Microwave Pretreatment for Biogas Enhancement through Anaerobic Digestion of Microalgal Biomass", Periodica Polytechnica Chemical Engineering, 63(1), pp. 65-72, 2019. https://doi.org/10.3311/PPch.12334

[13] Salama, E. S., Kurade, M. B., Abou-Shanab, R. A. I., El-Dalatony, M. M., Yang, I. S., Min, B., Jeon, B. H. "Recent progress in microalgal biomass production coupled with wastewater treatment for biofuel generation", Renewable and Sustainable Energy Reviews, 79, pp. 1189-1211, 2017. https://doi.org/10.1016/j.rser.2017.05.091

[14] Zaidi, A. A., Khan, S. Z., Shi, Y. "Optimization of nickel nanoparticles concentration for biogas enhancement from green algae anaerobic digestion", Materials Today: Proceedings, 39(2), pp. 1025-1028, 2021. https://doi.org/10.1016/j.matpr.2020.04.762

[15] Passos, F., Carretero, J., Ferrer, I. "Comparing pretreatment methods for improving microalgae anaerobic digestion: Thermal, hydrothermal, microwave and ultrasound", Chemical Engineering Journal, 279, pp. 667-672, 2015. https://doi.org/10.1016/j.cej.2015.05.065

[16] Dai, Y., Si, M., Chen, Y., Zhang, N., Zhou, M., Liao, Q., Shi, D. Liu, Y. "Combination of biological pretreatment with $\mathrm{NaOH} / \mathrm{Urea}$ pretreatment at cold temperature to enhance enzymatic hydrolysis of rice straw", Bioresource Technology, 198, pp. 725-731, 2015. https://doi.org/10.1016/j.biortech.2015.09.091

[17] Khalid, M. J., Zeshan, Waqas, A., Nawaz, I. "Synergistic effect of alkaline pretreatment and magnetite nanoparticle application on biogas production from rice straw", Bioresource Technology, 275, pp. 288-296, 2019. https://doi.org/10.1016/j.biortech.2018.12.051

[18] Appels, L., Houtmeyers, S., Degrève, J., Van Impe, J., Dewil, R. "Influence of microwave pre-treatment on sludge solubilization and pilot scale semi-continuous anaerobic digestion", Bioresource Technology, 128, pp. 598-603, 2013. https://doi.org/10.1016/j.biortech.2012.11.007 
[19] Mendez, L., Mahdy, A., Demuez, M., Ballesteros, M., GonzálezFernández, C. "Effect of high pressure thermal pretreatment on Chlorella vulgaris biomass: Organic matter solubilisation and biochemical methane potential", Fuel, 117, pp. 674-679, 2014. https://doi.org/10.1016/j.fuel.2013.09.032

[20] Lee, J. Y., Yoo, C., Jun, S. Y., Ahn, C. Y., Oh, H. M. "Comparison of several methods for effective lipid extraction from microalgae", Bioresource Technology, 101(1), pp. S75-S77, 2010. https://doi.org/10.1016/j.biortech.2009.03.058

[21] Deepanraj, B., Sivasubramanian, V., Jayaraj, S. "Effect of substrate pretreatment on biogas production through anaerobic digestion of food waste", International Journal of Hydrogen Energy, 42(42), pp. 26522-26528., 2017. https://doi.org/10.1016/j.ijhydene.2017.06.178

[22] Liu, X., Hiligsmann, S., Gourdon, R., Bayard, R. "Anaerobic digestion of lignocellulosic biomasses pretreated with Ceriporiopsis subvermispora", Journal of Environmental Management, 193, pp. 154-162, 2017. https://doi.org/10.1016/j.jenvman.2017.01.075

[23] Zaidi, A. A., Feng, R., Malik, A., Khan, S. Z., Shi, Y., Bhutta, A. J., Shah, A. H. "Combining Microwave Pretreatment with Iron Oxide Nanoparticles Enhanced Biogas and Hydrogen Yield from Green Algae", Processes, 7(1), Article number: 24, 2019. https://doi.org/10.3390/pr7010024

[24] Ramachandra, T. V, Hebbale, D. "Bioethanol from macroalgae: Prospects and challenges", Renewable and Sustainable Energy Reviews, 117, Article number: 109479, 2020. https://doi.org/10.1016/j.rser.2019.109479

[25] Pattra, S., Sangyoka, S., Boonmee, M., Reungsang, A. "Biohydrogen production from the fermentation of sugarcane bagasse hydrolysate by Clostridium butyricum", International Journal of Hydrogen Energy, 33(19), pp. 5256-5265, 2008.

https://doi.org/10.1016/j.ijhydene.2008.05.008
[26] Ivanova, G., Rákhely, G., Kovács, K. L. "Thermophilic biohydrogen production from energy plants by Caldicellulosiruptor saccharolyticus and comparison with related studies", International Journal of Hydrogen Energy, 34(9), pp. 3659-3670, 2009. https://doi.org/10.1016/j.ijhydene.2009.02.082

[27] Fang, W., Zhang, P., Zhang, X., Zhu, X., van Lier, J. B., Spanjers, H. "White rot fungi pretreatment to advance volatile fatty acid production from solid-state fermentation of solid digestate: Efficiency and mechanisms", Energy, 162, pp. 534-541, 2018. https://doi.org/10.1016/j.energy.2018.08.082

[28] American Public Health Association Inc. "Standard Methods for the Examination of Water and Wastewater", American Public Health Association Inc. (APHA), New York, NY, USA, 1995.

[29] Kavitha, S., Preethi, J., Rajesh Banu, J., Yeom, I. T. "Low temperature thermochemical mediated energy and economically efficient biological disintegration of sludge: Simulation and prediction studies for anaerobic biodegradation", Chemical Engineering Journal, 317, pp. 481-492, 2017. https://doi.org/10.1016/j.cej.2017.02.092

[30] Córdova, O., Passos, F., Chamy, R. "Physical Pretreatment Methods for Improving Microalgae Anaerobic Biodegradability", Applied Biochemistry and Biotechnology, 185(1), pp. 114-126, 2018. https://doi.org/10.1007/s12010-017-2646-6

[31] Zaidi, A. A., RuiZhe, F., Shi, Y., Khan, S. Z., Mushtaq, K. "Nanoparticles augmentation on biogas yield from microalgal biomass anaerobic digestion", International Journal of Hydrogen Energy, 43(31), pp. 14202-14213, 2018. https://doi.org/10.1016/j.ijhydene.2018.05.132

[32] Zaidi, A. A., Khan, S. Z., Almohamadi, H., Mahmoud, E. R. I., Naseer, M. N. "Nanoparticles Synergistic Effect with Various Substrate Pretreatment and their Comparison on Biogas Production from Algae Waste", Bulletin of Chemical Reaction Engineering \& Catalysis, 16(2), pp. 374-382, 2021. https://doi.org/10.9767/bcrec.16.2.10637.374-382 